\title{
A REMIÇÃO DA PENA PELA LEITURA: UMA ANÁLISE DA RESOLUÇÃO No 391/2021 DO CONSELHO NACIONAL DE JUSTIÇA E DAS NOVAS PERSPECTIVAS DE REINSERÇÃO SOCIAL
}

\author{
THE REMISSION OF SENTENCE FOR READING: AN \\ ANALYSIS OF THE RESOLUTION No 391/2021 OF NATIONAL \\ COUNCIL OF JUSTICE AND THE NEW PERSPECTIVES OF \\ SOCIAL REINSERTION
}

\section{Guilherme Augusto Volles ${ }^{1}$ Ana Luisa Fernandes Naatz ${ }^{2}$}

Resumo: No direito contemporâneo, a sanção penal tem como objetivo punir o indivíduo responsável pela prática da conduta considerada criminosa e prevenir o cometimento de novos delitos. Seu caráter preventivo não é fundado apenas no medo da punição, mas também na reinserção gradual do indivíduo transgressor na vida em sociedade. Em um Estado de Coisas Inconstitucional, reconhecido pelo Supremo Tribunal Federal e marcado por sucessivas violações aos direitos fundamentais das pessoas presas, é necessário que os órgãos da execução penal incentivem a aplicação de mecanismos capazes de enfrentar as

1. Pós-graduando em Direito Aplicado e em Gestão do Conhecimento na Magistratura pela Universidade Regional de Blumenau (FURB). Bacharel em Direito pela Universidade Regional de Blumenau (FURB). Aluno do Módulo "Práticas Jurídicas" da Escola Superior da Magistratura do Estado de Santa Catarina (ESMESC). Integrante dos Grupos de Pesquisa "Estado, Sociedade e Relações Jurídicas Contemporâneas" e "DTIn-FURB - Direito, Tecnologia e Inovação", certificados pela FURB junto ao CNPq. Residente Judicial na $1^{\text {a }}$ Vara Criminal de Blumenau, vinculado ao Poder Judiciário do Estado de Santa Catarina. E-mail: guilherme.a.volles@gmail.com.

2. Graduanda em Direito pela Universidade Regional de Blumenau (FURB). Estagiária na $3^{\text {a }}$ Vara Criminal de Blumenau, vinculada ao Poder Judiciário do Estado de Santa Catarina. E-mail: naatzana@hotmail.com. 
dificuldades do cenário de crise presente. Nesse panorama, a pesquisa busca compreender de que forma a remição da pena pela leitura, após a edição da Resolução no 391/2021 pelo Conselho Nacional de Justiça (CNJ), pode contribuir para a concretização de um modelo constitucional de cumprimento de pena que permita a reinserção dos indivíduos presos na vida em sociedade. Desse modo, inicialmente se dispõe sobre os fundamentos da pena e os princípios aplicáveis, com enfoque no instituto da remição e em suas balizas legais para, na sequência, identificar as mudanças normativas advindas da regulamentação do tema pelo CNJ e as possibilidades decorrentes do estímulo à leitura e ao letramento das pessoas privadas de liberdade. $\mathrm{O}$ estudo parte do método de abordagem dedutivo, adotando os procedimentos histórico e descritivo e fazendo uso das pesquisas documental e bibliográfica. A pesquisa revelou que a remição da pena e, em especial, a remição pela leitura contribuem para o enfrentamento do Estado de Coisas Inconstitucional que atinge o sistema prisional brasileiro, notadamente porque o acesso à literatura e à informação complementa os esforços pedagógicos empenhados com a oferta dos demais níveis de ensino às pessoas presas. Ao permitir a oferta à pessoa privada de liberdade de uma formação cultural completa, o acesso às obras literárias fornece as bases para evitar novas condutas delitivas, de modo a promover a reinserção na vida em sociedade e concretizar a garantia fundamental de individualização da pena.

Palavras-chave: Sanção penal. Remição. Estado de Coisas Inconstitucional. Estímulo à leitura. Formação cultural.

Abstract: On Contemporary Law, the penal sanction aims to punish the individual responsible for the conduct considered to be criminal and to prevent commission of crimes. Its preventive character is not only based on fear of punishment, but also the gradual social reinsertion of the transgressor into life in society. In an Unconstitutional State of Affairs, recognized by the Supreme Court and marked for successive violations of prisoner's fundamental rights, it is necessary that the criminal enforcement agencies encourage the application of mechanisms capable of facing the difficulties of the present crisis scenario. In this situation, this research aims to understand how the remission for reading, after the edition of Resolution $n^{\circ} 391 / 2021$ by the National Council of Justice, can contribute to the achievement of a constitutional model of serving a sentence that allows the reinsertion of prisoners in soci- 
ety. Thus, initially it lays out the fundamentals of the criminal penalty and the applicable principles, focusing on the institute of remission and its legal guidelines, to identify the normative changes arising from the regulation of the subject by the National Council and the possibilities arising from stimulate reading and literacy of people deprived of liberty. The study starts from the deductive approach method, adopting historical and descriptive procedures and making use of documentary and bibliographic research. The research revealed that the remission of the sentence and, in particular, the remission for reading, contribute to the confrontation of the Unconstitutional State of Affairs that affects the Brazilian prison system, notably because the access to literature and information complements the pedagogical efforts made with the offer of other levels of education to prisoners. By allowing the person deprived of liberty to be offered a complete cultural education, access to literary works provides the basis for avoiding commission of crimes, in order to promote the reintegration into life in society and fulfill the fundamental guarantee of individualization of the sentence.

Keywords: Penal sanction. Remission of the sentence. Unconstitutional State of Affairs. Encouragereading._Cultural education.

\section{INTRODUÇÃO}

O fundamento do poder punitivo do Estado historicamente foi objeto de intensas discussões teóricas, o que refletiu na construção de conceitos oriundos dos mais diversos contextos sociopolíticos e culturais. Em comum, tais propostas costumam embasar-se na retribuição pela prática de crimes e no desestímulo para que estes sejam cometidos.

Em um panorama contemporâneo, a finalidade da pena comporta uma retribuição pelo injusto causado ao bem jurídico tutelado e à sociedade afetada pela violação de uma regra geral imposta pela legislação penal. Ao mesmo tempo, possui um caráter preventivo, fundado tanto no medo de uma sanção, como na reinserção do indivíduo transgressor na vida social.

Para que sejam alcançados tais objetivos, necessário serem observados os princípios e as diretrizes constitucionais e infraconstitucionais que norteiam o cumprimento de pena. Previstos expressamente na Car- 
ta Magna, na Lei de Execução Penal (LEP) ou resultantes de uma interpretação sistemática da doutrina pátria, tais preceitos funcionam como verdadeiros comandos a serem observados pelos órgãos que intervêm na execução. Trata-se, em outros termos, de buscar a concretização de um modelo constitucional de Estado, construído em um contexto democrático e pautado no reconhecimento e na valorização dos direitos e das garantias individuais fundamentais.

Em um cenário marcado pela existência de sérias dificuldades de assegurar direitos fundamentais às pessoas presas, denominado de Estado de Coisas Inconstitucional pelo Supremo Tribunal Federal no julgamento da Arguição de Descumprimento de Preceito Fundamental (ADPF) 347/DF, tais ponderações são ainda mais prementes. Isso porque se reconheceu como dever dos diversos órgãos da execução penal adotar e estimular mecanismos idôneos para enfrentar - ou, ao menos, minimizar - as mazelas do sistema prisional brasileiro.

Nesse cenário, a remição pode ser trazida à análise como um instituto que prevê a redução do tempo de cumprimento de pena pela dedicação do preso ao trabalho e ao estudo. Por meio dela, objetiva-se o desenvolvimento pessoal do apenado e o fornecimento de meios para que seja reinserido na vida social, sem que torne a delinquir. Do mesmo modo, por razões de política criminal, evita-se que o indivíduo permaneça encarcerado em condições por vezes precárias ao tempo em que já demonstrou condições de retornar ao estado de liberdade.

Ocorre que, para além da previsão expressa na Lei de Execução Penal, a prática forense tem ampliado as hipóteses de seu cabimento. $\mathrm{O}$ maior exemplo da evolução do instituto é a possibilidade de remição da pena pela leitura, regulamentada de maneira detalhada e em caráter nacional com a Resolução n ${ }^{0}$ 391, de 10 de maio de 2021, do Conselho Nacional de Justiça (CNJ).

A partir dessas premissas, este artigo foi idealizado com o propósito de delinear os principais contornos jurídicos para compreender de que forma a remição da pena pela leitura, após a edição de um regramento nacional pelo $\mathrm{CNJ}$, pode contribuir para a concretização de um modelo constitucional de cumprimento da sanção penal e que permita a reinser- 
ção dos presos na vida em sociedade. Para tanto, estrutura-se a pesquisa em três grandes momentos: o primeiro destinado a identificar os fundamentos da pena e a principiologia aplicável, notadamente com enfoque no instituto da remição e em suas balizas legais; o segundo direcionado à compreensão das mudanças normativas advindas da edição da Resolução no 391/2021 do CNJ para o implemento de programas de estímulo à leitura nas unidades prisionais; e o terceiro orientado ao estudo conjunto das premissas da remição e das possibilidades decorrentes do estímulo à leitura e ao letramento das pessoas privadas de liberdade.

\section{A EXECUÇÃO PENAL NO DIREITO CONTEMPORÂNEO: FUNDAMENTOS E PREMISSAS DA REMIÇÃO DA PENA}

No momento em que o sujeito imputável pratica um ato definido como crime, transgredindo a norma jurídica vigente, surge para o Estado o direito de puni-lo. A sanção penal é, portanto, o exercício do direito estatal de limitar um direito subjetivo do transgressor, aplicando uma pena proporcional à conduta lesiva. Para tanto, é necessário que o agente seja culpável, que exista prévia proteção jurídica ao bem tutelado atingido e que a punição esteja legalmente prevista. Em todos os casos, deve a punição observar as regras inerentes ao devido processo legal e às demais garantias constitucionais.

Por evidente, o fundamento do poder punitivo não é unívoco. A depender da matriz teórica adotada e do contexto histórico vertente, tal compreensão transmuta-se em um ou mais fundamentos, que perpassam ideais de retribuição pela prática de ilícitos ou de prevenção ao seu cometimento (BITENCOURT, 2012). A seguir, serão abordadas, de maneira suscinta, as premissas que dão suporte ao poder-dever de punir estatal para, após, adentrar ao estudo do instituto da remição.

\subsection{Os fundamentos da pena e a principiologia aplicável}

No Iluminismo, o direito de punir e as penas tiveram origem e fundamento na teoria contratualista, baseada na compreensão de que os homens, cansados de viver em estado de terror, sacrificam parte de sua 
liberdade para gozar do restante com segurança. Entretanto, como os próprios autores daquele tempo afirmavam, a consequência da formação do pacto social é o despotismo: o desejo não era somente retirar da massa comum sua porção de direitos, mas de usurpar as dos demais. A solução para reprimir essas tendências despóticas dos indivíduos foi a criação das penas. Assim, o direito de punir repousa justamente na soma de todas as porções de direitos e liberdades cedidas no contrato social (BECCARIA, 1988).

Não se inclui no escopo deste estudo uma compreensão extensiva dos fundamentos do poder-dever de punir por parte do Estado. Busca-se, entrementes, identificar suas premissas em um modelo constitucional, notadamente porque pela "formalização de base democrática do controle social $[\ldots]$ o exercício do poder punitivo por parte do Estado vê-se limitado pelos princípios e garantias reconhecidos democraticamente pela sociedade" (BITENCOURT, 2012, p. 330). De outro modo, ainda que seja adotada atualmente uma teoria preventiva e prospectiva, de base relativista, não se abandona o princípio da culpabilidade como suporte da imposição da pena por um fato passado, na ideia de retribuição, sem incorrer em qualquer contradição teórica quanto à compreensão da pena a partir de diversas finalidades.

No âmbito judiciário, a pretensão punitiva ou jus puniendi, na acepção latina, é materializada em uma sentença condenatória, que contém a pena aplicada ao indivíduo, proporcional ao delito cometido e demais circunstâncias subjetivas e objetivas relacionadas ao ato lesivo e ao infrator em questão. Consoante o art. 59 do Código Penal, a pena imposta serve tanto como retribuição ao mal causado ao bem jurídico tutelado e à sociedade, como possui caráter preventivo. Segundo Guilherme de Souza Nucci (2020, p. 281), esse caráter preventivo se desdobra em quatro aspectos: geral negativo, que corresponde ao poder intimidatório que causa em todo o corpo social; geral positivo, que demonstra a eficiência do Direito Penal; especial negativo, que significa a intimidação do infrator em questão para que não reincida ao ato criminoso; e, por fim, especial positivo, com vistas à reinserção do indivíduo na sociedade, por meio da disponibilização das estruturas e dos mecanismos 
necessários para ressocialização do apenado, notadamente na execução penal.

A execução penal é a fase processual em que se executa o título judicial, ou seja, a sentença condenatória ou decisão criminal, com vistas a atingir as finalidades da pena. Além desse conceito, entende-se a execução penal como o conjunto de normas e princípios que tem por objetivo efetivar o comando judicial determinado tanto na sentença penal quanto nas medidas de segurança (AVENA, 2015). Para além dessas premissas, a própria Lei de Execução Penal (LEP) (Lei nº 7.210, de 11 de julho de 1984) estabelece, em seu art. $1^{\circ}$, que o objetivo da execução é "efetivar as disposições de sentença ou decisão criminal e proporcionar condições para a harmônica integração social do condenado e do internado" (BRASIL, 1984). Nesse sentido, é possível compreender a preferência do legislador sobre a teoria mista dos objetivos da pena, conforme já indicado.

Para efetivar o comando judicial e alcançar os objetivos previstos da pena, é necessário observar os princípios que norteiam o cumprimento da pena. Construídos extensivamente pela doutrina jurídica a partir do modelo constitucional de Estado e pelos dizeres da legislação penal vigente, seus preceitos funcionam como verdadeiros comandos a serem observados por todos os órgãos da execução penal (art. 61, LEP).

Nessa toada, a estrita observância do título exsurge como regra basilar dos processos de cumprimento de pena. Cabe ao juízo da execução conduzir e fiscalizar a execução da pena aplicada no processo de conhecimento, sem deduzir maiores incursões quanto ao mérito da pretensão punitiva estatal. Evidencia-se que a coisa julgada, que torna indiscutível o comando da sentença condenatória, é instrumento de pacificação social, de manutenção da ordem jurídica, e perfectibiliza o princípio da segurança jurídica.

Sobre sua importância da coisa julgada para o Direito Penal, Miguel Teixeira Souza (1997, p. 568) destaca:

[...] o caso julgado é uma exigência da boa administração da justiça, da funcionalidade dos tribunais e da salvaguarda da paz social, pois que evita que uma mesma ação seja instaurada várias vezes, obsta 
a que sobre a mesma situação recaiam soluções contraditórias e garante a resolução definitiva dos litígios que os tribunais são chamados a dirimir. Ela é, por isso, expressão dos valores de segurança e certeza que são imanentes a qualquer ordem jurídica.

Segundo o princípio da inderrogabilidade, havendo condenação e trânsito em julgado, a pena deve ser aplicada e integralmente cumprida. Oportuno destacar que não há qualquer contrariedade com outros institutos e benefícios previstos na lei de execução, como é o caso da progressão de regime, da suspensão condicional e da remição. Todas são práticas que contribuem para o alcance do propósito ressocializador da pena, isso porque fornecem oportunidades para que o condenado seja gradualmente reinserido na vida em sociedade (AVENA, 2015).

Tais institutos e, em especial a remição, foco desta pesquisa, são também reflexo do princípio da individualização da pena em sua fase executória. De matriz constitucional (art. $5^{\circ}, \mathrm{XLVI}, \mathrm{CF}$ ), preceitua que não há estrita padronização do cumprimento da condenação, pois circunstâncias e comportamentos individuais devem ser considerados. Em similar perspectiva, a intranscendência também constitui garantia fundamental a ser observada, pois "o processo e a pena, bem como a medida de segurança, não podem ir além da pessoa do autor da infração" (MARCÃO, 2021, p. 14).

Em se tratando de garantia fundamental, também é aplicado, no curso da execução, o chamado princípio da humanidade, decorrente da proteção da dignidade da pessoa humana, que veda as punições de caráter cruel e degradante (art. 5, XLVII, CF). Não por outro motivo, a sanção penal historicamente abandonou os grilhões, as correntes e os castigos corporais para incorporar um modelo que preserva a integridade corporal do preso e o respeito aos seus direitos como indivíduo (BRITO, 2020). Em proteção à própria natureza do ser humano, a observância de seu mínimo existencial "sempre permanece, em maior ou menor escala, até no pior delinquente" (DOTTI, 1998, p. 222).

Como se abordará oportunamente, o instituto da remição atua como um dos instrumentos que dão concretude a tais balizas constitucionais e infraconstitucionais, porque estimula o trabalho e o estudo para prepa- 
rar o indivíduo para o reingresso na vida social. Sendo de conhecimento geral as condições precárias de significativa parcela dos estabelecimentos prisionais brasileiros - nos quais faltam recursos e estruturas adequadas para comportar o quantitativo de detentos -, a oferta de oportunidades que permitam afastar do mundo do crime aqueles que uma vez transgrediram a legislação penal mostra-se ainda mais importante socialmente.

\section{2 $\mathrm{O}$ instituto da remição da pena}

Conforme a Exposição de Motivos da Lei de Execução Penal, a inserção da remição no ordenamento jurídico pátrio remonta ao direito penal espanhol das décadas de 1930 e 1940. A despeito de sua origem controversa - teria sido concebido durante a vigência de um governo adepto do fascismo que obrigava os prisioneiros de guerra ao trabalho em obras públicas -, atualmente o instituto representa notável conquista que prestigia a dignidade da pessoa humana e o princípio da individualização da pena (LEAL, 2012).

Em relação ao conceito em si, a remição se constitui no direito do sentenciado "reduzir o tempo de cumprimento da pena, contanto que se dedique rotineiramente ao trabalho e/ou estudo" (MARCÃO, 2021, p. 93). Seu fundamento legal exsurge dos art. 126 a 128 da Lei de Execução Penal, que definem os requisitos necessários para a obtenção do benefício e a proporção aplicada em seu cálculo.

Por expressa previsão legal, o desconto da pena pelo trabalho somente é cabível quando o apenado estiver alocado no regime fechado ou semiaberto (art. 126, LEP), uma vez que no regime aberto o exercício da atividade laboral lícita já é condição estabelecida na audiência admonitória - sendo requisito, portanto, para a progressão a esse regime. Por outro lado, a remição pelo estudo é admitida aos presos em regime aberto, em benefício do livramento condicional ou mesmo detidos cautelarmente (art. 126, $\S 6^{\circ}$, LEP), em razão da mudança legislativa trazida pela Lei no 12.433 , de 29 de junho de 2011. Procurou-se, em re- 
sumo, incentivar a alfabetização e a escolarização, corolários do dever de assistência educacional previsto pela própria lei de execução.

Embora a remição seja direito do apenado que labora ou frequenta programas de ensino formal dentro do ergástulo, a homologação de dias remidos não constitui direito adquirido nem faz coisa julgada. Isto porque, conforme dispõe o art. 127 da LEP, “em caso de falta grave, o juiz poderá revogar até $1 / 3$ (um terço) do tempo remido, observado o disposto no art. 57, recomeçando a contagem a partir da data da infração disciplinar" (BRASIL, 1984). Não difere o entendimento jurisprudencial do Superior Tribunal de Justiça, que reconhece se tratar de expectativa de direito:

[...] 8. A perda dos dias remidos em razão do cometimento de falta grave pelo sentenciado não ofende o direito adquirido ou a coisa julgada. $\mathrm{O}$ instituto da remição, como prêmio concedido ao apenado em razão do tempo trabalhado, gera, tão-somente, expectativa de direito, sendo incabível cogitar-se de reconhecimento de coisa julgada material. A própria Lei de Execução Penal estabelece nos arts. 50 e 127 que as faltas disciplinares de natureza grave impõem a perda dos dias remidos. Aplicação da Súmula Vinculante n. 9 do Supremo Tribunal Federal. [...] (BRASIL, 2012)

Sem o objetivo de esgotar o tema e de abordar as discussões doutrinárias pertinentes à perda dos dias remidos, convém destacar que o Supremo Tribunal Federal assentou a constitucionalidade da medida ao editar a Súmula Vinculante 9. O fundamento da sanção repousa justamente no fato de que o mau comportamento viola o objetivo do instituto, de promover o desenvolvimento pessoal do apenado e sua reinserção social (AVENA, 2015).

É de destacar, ainda, que a edição da Lei no 12.433/11 resolveu divergência outrora existente e definiu que "o tempo remido será computado como pena cumprida, para todos os efeitos" (BRASIL, 1984). Trata-se de alteração de considerável importância, porque diferentes interpretações impactavam diretamente nos prognósticos de benefícios e resultavam em cômputos diferentes, a depender do efeito considerado (MARCÃO, 2021). 
O cálculo do benefício é feito conforme a razão prevista no art. 126, $\S 1^{\circ}$, I e II, da Lei de Execução. Desse modo, considera-se remido 1 dia de pena a cada 12 horas de estudo ou 3 dias de trabalho. Ressalta-se ser possível a cumulação de ambas as formas de desconto, hipótese em que a jornada do preso será definida de modo compatível para o desempenho de ambas as atividades (art. 126, § $3^{\circ}$, LEP).

Mais recentemente, a prática forense tem ampliado as hipóteses de cabimento da remição da pena, ainda que sem mudança legislativa na esfera federal. O maior exemplo é desconto da pena pela leitura, a seguir tratada, cuja regulamentação advém da publicação da Resolução $n^{\circ}$ 391, de 10 de maio de 2021, do Conselho Nacional de Justiça.

\section{A REMIÇÃO DA PENA E O ESTÍMULO AO ESTUDO E À LEITURA: UMA ANÁLISE DA RESOLUÇÃO No 391/2021 DO CNJ}

Nos termos já expostos, por meio do instituto da remição o sentenciado pode reduzir o tempo de cumprimento de sua pena, desde que se dedique ao trabalho e/ou ao estudo de forma rotineira e com a observância às regras constantes nos arts. 126 a 128 da Lei de Execução Penal. Uma vez que se constitui "a reeducação uma das finalidades da pena, não há dúvida que o trabalho e o estudo são fortes instrumentos para tanto, impedindo a ociosidade perniciosa no cárcere" (NUCCI, 2021, p. 208).

Não se pode ignorar, todavia, que o desconto da pena pela frequência no estudo somente surgiu após intenso debate doutrinário e jurisprudencial, que resultou na edição da Súmula 341 do Superior Tribunal de Justiça. Na oportunidade, a corte assentou que a frequência a curso de ensino formal seria causa de remição de parte do tempo a cumprir nos regimes fechado ou semiaberto (BRASIL, 2007). Somente com a edição da Lei $n^{\circ}$ 12.433/11, que alterou dispositivos da LEP, o impasse foi resolvido em definitivo, e a legislação passou a prever de maneira expressa a possibilidade.

Nota-se que a reforma legislativa na LEP, à época, representou avanço em relação ao entendimento do STJ, vez que permitiu a remição pelo 
estudo ao preso em regime aberto, durante o benefício do livramento condicional e, inclusive, ao indivíduo preso cautelarmente (art. 126, $\S \S$ $6^{\circ}$ e $7^{\circ}$, LEP). O intuito da ampliação das hipóteses legais, além de uma adequada individualização da pena, foi estimular a reinserção social e propiciar a consciência da ilicitude por meio da alfabetização, do letramento e da cultura (BITENCOURT, 2012), temas de fundamental relevância para a construção de um sistema prisional aderente aos valores consagrados pela Constituição Federal.

Apesar dos notáveis avanços legislativos da década passada, outras modalidades de remição da pena não foram expressamente incluídas na Lei de Execução Penal, ainda que concebidas como iniciativas promissoras. Encaixam-se, nessa categoria, a remição pela prática de esportes, pela participação em atividades culturais e comunitárias e pela leitura, sendo que esta última representa o cerne deste estudo. Em comum, todas sofrem com a falta de disciplina normativa e, em razão disso, ficam, em sua maioria, restritas a iniciativas pontuais de determinados estabelecimentos prisionais e de varas especializadas (ROIG, 2016).

Segundo Rodrigo Duque Estrada Roig (2016), os alicerces da remição pela leitura surgiram com a Resolução no 14/1994 do Conselho Nacional de Política Criminal e Penitenciária (CNPCP), que estabeleceu a necessidade dos estabelecimentos prisionais contarem com biblioteca organizada de livros de cunho informativo, educativo e recreativo. Ainda segundo o autor, a Resolução no 03/2009 do mesmo órgão teria estabelecido que a educação no ambiente prisional deve estar associada a ações de fomento à leitura. No mesmo sentido, o Decreto Presidencial $\mathrm{n}^{\mathrm{o}} 7.626 / 2011$ introduziu, no ordenamento jurídico brasileiro, o Plano Estratégico de Educação no âmbito do Sistema Prisional (PEESP).

Essa forma de remição da pena também surge como decorrência do direito que as pessoas presas possuem de manter contato com o mundo exterior pela leitura ou outros meios de informação (art. 41, XV, LEP). Lembra-se que o art. 21 da Lei de Execução Penal, ao tratar da assistência educacional, dispõe que, "em atendimento às condições locais, dotar-se-á cada estabelecimento de uma biblioteca, para uso de todas 
as categorias de reclusos, provida de livros instrutivos, recreativos e didáticos" (BRASIL, 1984).

$\mathrm{Na}$ falta de dispositivos específicos que fornecessem balizas objetivas para concessão do direito à remição da pena pela leitura no âmbito federal, algumas unidades da federação - como é o caso dos Estados do Paraná e de São Paulo - editaram leis ou expediram portarias para regulamentar o instituto. $\mathrm{O}$ fundamento de tal disciplina decorre da natureza da questão em análise, que assume contornos de direito penitenciário, cuja competência legislativa é concorrente (art. 24, I, CF).

O cenário de carência normativa começou a ser enfrentado com a publicação da Recomendação ${ }^{\circ}$ 44, de 26 de novembro de 2013, do Conselho Nacional de Justiça. Por meio do ato, o órgão de controle do Poder Judiciário passou a orientar uma disciplina única para aferição e cálculo das horas a serem remidas pela prática de atividades de natureza cultural, esportiva e de saúde, desde que integradas a projetos político-pedagógicos das unidades prisionais. Quanto ao estudo, recomendou-se a concessão de bonificação de dias remidos nos casos de conclusão no Exame Nacional para Certificação de Competências de Jovens e Adultos (ENCCEJA) ou Exame Nacional do Ensino Médio (ENEM).

No tocante à leitura, o $\mathrm{CNJ}$ previu expressamente que era recomendado aos tribunais "estimular, no âmbito das unidades prisionais estaduais e federais, como forma de atividade complementar, a remição pela leitura, notadamente para apenados aos quais não sejam assegurados os direitos ao trabalho, educação e qualificação profissional" (BRASIL, 2013, p. 3). Ainda que o ato consistisse apenas em recomendação, traduziu-se em significativa evolução no implemento dessa forma de desconto de pena nos estabelecimentos prisionais do país. Afinal, pela primeira vez um órgão de expressão nacional regulamentou - ainda que em poucos dispositivos - um tema de tamanha relevância.

Fundado no aprofundamento gradual das discussões sobre a importância da remição - e do estímulo à educação e à cultura como um todo no sistema prisional -, o Conselho Nacional de Justiça finalmente editou a Resolução $n^{\circ} 391$, de 10 de maio de 2021. Trata-se, sem se olvidar da existência de diversas regulamentações locais, da mais significativa 
disciplina normativa sobre o "reconhecimento do direito à remição de pena por meio de práticas sociais educativas em unidades de privação de liberdade" (BRASIL, 2021a, p. 1). Isso porque reúne, em um único texto, as principais regras procedimentais sobre tal modalidade de desconto de pena, a partir do entendimento mais recente dos tribunais superiores.

Destaca-se que a referida resolução foi editada considerando a decisão da Segunda Turma do Supremo Tribunal Federal proferida em sede de agravo regimental no $\mathrm{HC} \mathrm{n}^{\circ} 190.806 / \mathrm{SC}$, julgado em 30 de março de 2021, e de relatoria do Min. Ricardo Lewandowski. Na oportunidade, a Corte reconheceu o direito à remição da pena pela leitura em razão do papel ressocializador em que se inserem as atividades educacionais e determinou a expedição de recomendação ao CNJ para que tomasse as medidas cabíveis para implementar a prática no sistema prisional e penitenciário brasileiro (BRASIL, 2021b).

Delineado o contexto que norteou a edição da Resolução no 391/2021, importa identificar que o texto normativo tratou expressamente de reconhecer, em seu art. $2^{\circ}$, que o direito à "remição de pena por meio de práticas sociais educativas considerará as atividades escolares, as práticas sociais educativas não-escolares e a leitura de obras literárias" (BRASIL, 2021a, p. 3).Em relação à primeira, o ato consolida o entendimento firmado pelo STF quanto à base de cálculo para o cômputo de horas remidas pela aprovação no ENCCEJA e no ENEM (art. $3^{\circ}$, $\S$ único), ou seja, 1.600 horas para os anos do Ensino Fundamental e 1.200 horas para o Ensino Médio ou educação profissional. Em relação à segunda, foram exigidos requisitos para que projetos fossem considerados como atividades educativas não escolares, dentre as quais, a definição de objetivos, a adoção de referenciais teóricos e metodológicos, o registro de frequência e participação e a definição de carga horária e de responsável pelo acompanhamento (art. $4^{\circ}$ ).

No tocante à leitura, previu-se, em seu art. $5^{\circ}$, que farão jus ao direito de desconto "as pessoas privadas de liberdade que comprovarem a leitura de qualquer obra literária, independentemente de participação em projetos ou lista prévia de títulos autorizados" (BRASIL, 2021a, p. 5). 
A atividade terá caráter voluntário, diferentemente do que ocorre com o trabalho e com o ensino de primeiro grau, que são obrigatórios por expressa previsão legal (arts. 18 e 31 , LEP).

As obras literárias a serem utilizadas no programa de remição serão aquelas constantes no acervo da biblioteca da unidade prisional, que poderá ser renovado por meio de doações de visitantes ou organizações da sociedade civil (art. 5 I e II). O acesso ao acervo será assegurado a todas as pessoas em cumprimento de pena ou medida de segurança, independentemente do regime ou situação disciplinar, bem como aos presos ou internados cautelarmente (inc. III). Trata-se, novamente, de inequívoco desdobramento do dever do Estado de prestar assistência educacional ao preso, inclusive mediante o fornecimento de livros instrutivos, recreativos e didáticos (art. 21, LEP), bem como ao direito que o detido possui de manter contato com o meio exterior através da correspondência escrita, da leitura e de outros recursos de informação (art. 41, XV, LEP).

A resolução em análise fez questão de destacar em, ao menos, três oportunidades que é "vedada toda e qualquer censura a obras literárias, religiosas, filosóficas ou científicas, nos termos dos art. $5^{\circ}$, IX, e $220, \S$ $2^{\circ}$, da Constituição Federal" (BRASIL, 2021a, p. 5). Procurou o CNJ, em efetivo, concretizar os preceitos constitucionais da livre expressão da atividade intelectual, científica e de comunicação, tal como o direito de acesso à informação, protegendo-o de práticas expressas ou veladas de censura.

Em relação aos procedimentos a serem seguidos para a obtenção do benefício, a atual normativa partiu dos critérios já traçados pela Recomendação no 44/2013 do CNJ. Em suma, será necessário que a pessoa em privação de liberdade registre o empréstimo da obra desejada, momento em que terá o prazo de 21 a 30 dias para realizar a sua leitura. Em até 10 dias após esse período, o interessado deverá apresentar um relatório de leitura sobre a obra em questão, conforme roteiro fornecido pelo juízo da execução ou por uma Comissão de Validação especialmente designada (art. 5º IV). 
Cada obra lida corresponderá à remissão de 4 dias de pena, limitando-se, durante o período de 12 meses, a até 12 obras efetivamente lidas e avaliadas ( $\operatorname{art} .5^{\circ}, \mathrm{V}$ ). Desse modo, assegura-se a possibilidade de o preso remir até 48 dias de sua pena a cada intervalo de um ano. Importante destacar que a validação do relatório de leitura "não assumirá caráter de avaliação pedagógica ou de prova, devendo limitar-se à verificação da leitura e ser realizada no prazo de 30 (trinta) dias contados da entrega do documento [...]" (BRASIL, 2021a, p. 6).

A análise do relatório competirá à Comissão de Validação, que deverá ser instituída pelo juízo competente (art. $5^{\circ}, \S 1^{\circ}$ ). Inovando em relação à Recomendação no 44/2013 do CNJ, a Resolução no 391/2021 previu que o grupo de trabalho terá composição multipartite e contará com a participação de membros do Poder Executivo ligados aos órgãos gestores da educação e responsáveis pelas políticas educacionais no sistema prisional, de docentes e bibliotecários que atuam na unidade, de representantes da sociedade civil, de iniciativas autônomas e de instituições de ensino privadas ou públicas, além de pessoas privadas de liberdade e familiares de indivíduos detidos.

No exercício de suas atividades, a Comissão aferirá o registro elaborado pela pessoa privada de liberdade segundo seu grau de letramento, alfabetização e escolarização, e considerará a estética textual, a fidedignidade e a clareza do texto. Como esse grupo não exerce atividades de natureza educacional - atribuição de outros órgãos dentro do sistema prisional -, "'a validação do relatório de leitura não assumirá caráter de avaliação pedagógica ou de prova, devendo limitar-se à verificação da leitura [...]" (BRASIL, 2021a, p. 6).

O CNJ também procurou garantir o aproveitamento dessa modalidade de remição por presos de diversos níveis de escolaridade, porque "a isonomia ou igualdade não equivale à simples equiparação de todos os condenados, mesmo porque os homens não são iguais, e suas diferenças são importantes e devem ser consideradas na execução de sua pena" (BRITO, 2020, p. 66). Assim, as unidades prisionais e as Comissões de Validação deverão prever formas de auxílio para fins de validar relatórios de pessoas em fase de alfabetização. Podem, para tanto, estimular 
o uso de técnicas de leitura de audiobooks, permitir a apresentação do relatório de forma oral ou o registro do conteúdo lido por outras formas de expressão, como a realização de pinturas ou desenhos, a depender da condição do indivíduo (art. $5^{\circ}, \S 2^{\circ}$ ). Do mesmo modo, o Poder Público deverá assegurar a disponibilização de livros em braile ou audiobooks para pessoas com deficiência visual ou intelectual $\left(\S 3^{\circ}\right)$.

A resolução também previu que a possibilidade de a pessoa privada de liberdade participar de projetos de remição pela leitura ou por práticas sociais educativas não escolares não afastará a remição pelo trabalho ou pela educação formal escolar (art. $7^{\circ}$ ). Desse modo, em atendimento ao comando previsto no art. $126, \S 3^{\circ}$, LEP, “as horas diárias de trabalho e de estudo serão definidas de forma a se compatibilizarem" (BRASIL, 1984), sendo plenamente cabível a cumulação dos benefícios.

Para que seja realizada a homologação dos dias remidos, a direção do estabelecimento encaminhará semestralmente a relação das pessoas que adquiriram o direito, podendo esse prazo ser individualmente reduzido para os casos dos indivíduos que estejam na iminência de progredir de regime (art. $\left.7^{\circ}, \mathrm{I}\right)$. Em homenagem ao dever de informação e de transparência, o preso deverá ter acesso à relação dos dias que conseguiu remir (inc. II).

Mais que estabelecer regras operacionais para a validação da leitura como forma de remir a pena, a Resolução no 391/2021 do CNJ ainda inovou ao definir, de maneira expressa, que compete ao juiz da execução zelar para que as unidades prisionais desenvolvam projetos de fomento e qualificação da leitura (art. $6^{\circ}$ ). Para tanto, poderão desenvolver parcerias com iniciativas de indivíduos presos ou seus familiares, organizações da sociedade civil, instituições de ensino ou órgãos públicos de educação, cultura e direitos humanos.

Por último, previu-se que o Poder Judiciário, por meio dos Grupos de Monitoramento e Fiscalização do Sistema Carcerário, articulará com os demais órgãos da execução penal e da sociedade civil a garantia do direito às práticas sociais educativas a todas as pessoas presas ou internadas. Dentre as atribuições, incluem-se: assegurar o acesso universal aos livros, trabalhar em prol da renovação do acervo, permitir o acesso 
às informações quanto aos programas e às práticas desenvolvidos nas unidades, garantir a articulação com os planos estaduais de educação e zelar pela célere comunicação entre os estabelecimentos prisionais e penitenciários e as varas de execução.

\section{O EXERCÍCIO DA LEITURA NO CURSO DA EXECUÇÃO DA PENA: EM BUSCA DE NOVOS SENTIDOS E PERSPECTIVAS DE REINSERÇÃO SOCIAL}

Delineadas as premissas jurídicas que sustentam o instituto da remição e seu atual panorama normativo, necessário pontuar sua importância - especialmente quando operada pela leitura - para o alcance de um modelo constitucional de cumprimento de pena. $\mathrm{O}$ emprego de institutos que possibilitem a efetiva reinserção do indivíduo na vida em sociedade faz parte desse cenário.

Nesse sentido, tem-se que remição é um instituto completo, pois reeduca o indivíduo, "prepara-o para sua reincorporação à sociedade, proporciona-lhe meios para reabilitar-se diante de si mesmo e da sociedade, disciplina sua vontade, favorece a sua família e sobretudo abrevia a condenação, condicionando esta ao próprio esforço do penado" (DIAS, citada por MIRABETE, 2000, p. 425-426). Logo, seu propósito transcende em muito a simples redução do tempo de cumprimento de pena, vez que se relaciona com a própria busca de uma harmônica integração social do condenado, um dos objetivos trazidos pela Lei $n^{0}$ 7.210/84 e que norteia toda a execução.

Não por outro motivo, a remição se transformou desde a edição da Lei de Execução Penal, pois, se originalmente abarcava apenas hipóteses relacionadas ao desempenho de atividades laborativas, mudanças legislativas pacificaram divergências travadas pela doutrina e pela jurisprudência quanto à possibilidade de o instituto englobar também a atividade de estudo regular. Recentemente, a Resolução no 391/2021 do CNJ disciplinou nacionalmente a possibilidade de remição pela leitura, o que consolida iniciativas promissoras desenvolvidas em diversas unidades prisionais e encampadas por vários tribunais. 
Tal evolução decorre da revalorização da execução como instrumento de reinserção do condenado na vida social. A faceta preventiva da pena - ou seja, o desestímulo à prática de condutas criminosas - também perpassa a reabilitação do indivíduo, sobretudo possibilitando o acesso a direitos até então não lhe assegurados. Nesses termos:

[...] considerando que o trabalho e a educação são direitos sociais (art. $6^{\circ}$ da $\mathrm{CF}$ ) e que a remição é instituto concebido para o benefício das pessoas presas, sua interpretação, aplicação e extensão devem ser as mais amplas possíveis, inclusive com a admissão da analogia in bonam partem. (ROIG, 2016, p. 242, grifo no original).

Assim, assume-se que a interpretação mais adequada da própria legislação relativa ao cumprimento de pena é aquela "que mais favoreça a sociedade e o preso, e por aqui não é possível negar que a dedicação rotineira deste ao aprimoramento de sua cultura contribui decisivamente para os destinos da execução" (MARCÃO, 2021, p. 94). Na esteira do raciocínio do autor, o estudo em sentido amplo - não somente o ensino regular - contribui de maneira decisiva para a readaptação do indivíduo à vida social em liberdade. Ao se possibilitar que este acesse programas de formação e desenvolvimento pessoal, está-se tomando medidas que diminuem as chances de que volte a delinquir.

Não se olvida da existência de severas barreiras impostas pela própria sociedade na inclusão desses indivíduos, poisa estigmatização da figura dos egressos do sistema prisional, reforçada pelas mídias tradicionais, envolve a sociedade numa atmosfera do medo, que tende a perpetuar a marginalização e negar-lhes, não raros os casos, oportunidades de trabalho.A oferta de trabalho e do estudo, inclusive profissionalizante, além do acesso à leitura, exsurge como um instrumento potencialmente eficaz de minimização dessa tendência.

A ampliação do número de hipóteses de cabimento da remição, desse modo, é notável incentivo à formação intelectual e profissionalizante do apenado, fornecendo-lhe meios adequados para sua ressocialização. Em similar perspectiva, é a lição de Renato Marcão (2021, p. 94), segundo o qual "não raras vezes o estudo acarretará melhores e mais sen- 
síveis efeitos no presente e no futuro do sentenciado, vale dizer, durante o período de cumprimento de pena e no momento da reinserção social, do que o trabalho propriamente dito".

As mesmas razões que justificam a oferta do ensino regular e profissionalizante aos presos (art. 17, LEP) e que sustentam a remição pelo estudo (art. 126, LEP) aplicam-se à leitura. Isso porque o direito do preso à informação e à leitura, previsto no art. 41, XV, da Lei de Execução Penal, é decorrência dos direitos fundamentais à informação e à educação, este último também um dever do Estado (art. 205, CF). Por essa razão, "situa-se na esfera da garantia do mínimo existencial, especialmente naquilo em que este [...] abrange uma dimensão sociocultural e não se limita a um mínimo vital" (SARLET; MARINONI; MITIDIERO, 2017, p. 691).

Por sua vez, na ótica político-criminal, a educação é um elemento irrenunciável e representa uma intervenção especialmente dirigida a assegurar interesses humanos, culturais e profissionais da pessoa presa (BRITO, 2020). Com a atual normativa do CNJ, a leitura passa a, efetivamente, ser incluída nesse panorama, situação que afasta vozes contrárias ainda presentes, que rejeitavam ou viam com desinteresse a chegada das bibliotecas às unidades prisionais. Com a edição da Resolução no 391/2021 do CNJ, passou a ser inequívoca a necessidade de o Poder Judiciário exercer papel fiscalizador na realização de projetos e iniciativas que concretizem esse direito fundamental.

À vista de um direito fundamental, descabe a alegação de que faltam recursos financeiros para aparelhar a estrutura dos estabelecimentos prisionais com vistas a permitir a educação dos apenados, seja pelo ensino regular, seja pela leitura. Mais que isso, a implementação de tais programas admite expressamente a formação de parcerias com órgãos públicos e instituições e organizações privadas, não sendo admissível a negativa genérica ao oferecimento dessa possibilidade ao detento:

A concretização da política penitenciária de desconto da pena pela leitura, portanto, além de constituir verdadeiro incentivo à educação do preso, passou a proporcionar ampla democratização do acesso às formas de remição penal para a população carcerária, já que 
sua realização prescinde de grande estruturação do estabelecimento penal, bastando que a penitenciária disponha de uma biblioteca, com no mínimo 20 exemplares de cada obra literária, além de uma equipe responsável pelo acompanhamento da medida. (OÑORO; SPEXOTO, 2020, p. 23).

Ainda, tem-se que o incentivo à leitura promovido pela remição está de acordo com a Política Nacional de Leitura e Escrita (PNLE), instituída pela Lei $n^{\circ} 13.693$, de 12 de julho de 2018. O objetivo da legislação é, em resumo, universalizar o acesso aos livros, à leitura, à escrita, à literatura e às bibliotecas de acesso público no Brasil, o que não exclui aquelas situadas no interior dos estabelecimentos de cumprimento de pena.

Com a resolução do $\mathrm{CNJ}$, o cenário também é favorável à difusão de novas iniciativas de leitura para remição da pena, assim como contribui para o fortalecimento das já existentes. No Estado de Santa Catarina, por exemplo, elenca-se o projeto "Despertar pela Leitura", desenvolvido desde o ano de 2016 e originado de uma parceria entre a Secretaria de Administração Prisional e Socioeducativa (SAP) e a Secretaria de Educação (SED). Conforme o último levantamento da Gerência de Educação, do Departamento de Administração Prisional (Geduc/ DEAP), cerca de 6.600 pessoas privadas de liberdade participam do programa e buscam diminuir seu tempo de pena por meio da leitura em, ao menos, 48 estabelecimentos prisionais e penitenciários (REGRAMENTO..., 2021).

Apesar da dimensão assumida com o passar dos anos, as condições aplicadas por diversos juízes do Estado eram fundadas na jurisprudência prevalecente dos tribunais e na recomendação do Conselho Nacional de Justiça então vigente. Agora, com um regramento nacional unificado, a tendência é de que as decisões sejam proferidas com mais segurança, em razão de afastadas as controvérsias existentes.

Igualmente, é de se destacar que o incentivo à leitura contribui também para o desencarceramento no sistema prisional, uma vez que, por meio dessa forma de remição, se reduz o tempo de pena a cumprir. Não se pode esquecer que o Supremo Tribunal Federal reconheceu, na 
ADPF 347/DF, julgada em 9 de setembro de 2015, de relatoria do Min. Marco Aurélio, a existência de Estado de Coisas Inconstitucional no sistema prisional brasileiro, marcado por violações reiteradas aos direitos humanos das pessoas presas e pela ausência de estrutura e recursos para a manutenção adequada dos estabelecimentos. Para enfrentar esse cenário de crise estrutural, a Corte também assentou que cabe a todos os órgãos da execução penal traçar planos e propor alternativas idôneas com vistas a resguardar direitos e contribuir para a melhoria das condições impostas aos indivíduos privados de sua liberdade.

Assim, o instituto analisado passa a ser um meio de amenizar o impacto do cárcere sobre os direitos fundamentais dos apenados. Além disso, como política criminal, pode ser um instrumento promissor no enfrentamento da superlotação dos presídios e penitenciárias brasileiros, desde que seja oportunizado de maneira séria e responsável.

Logo, apesar da intrigante inspiração do legislador quanto à origem da remição - como visto, ligada ao trabalho desempenhado pelos presos de guerra -, o instituto se transformou em notável conquista do direito penal brasileiro. A partir dela, pode-se promover o desencarceramento e concretizar a garantia fundamental de individualização da pena, decorrência da máxima da dignidade da pessoa humana. Além disso, viabiliza-se, de maneira mais efetiva, a reinserção da pessoa presa na vida social, contribuindo para o alcance das finalidades da pena e o aprimoramento do modelo democrático de Estado encampado pela Constituição Federal de 1988.

\section{CONCLUSÃO}

A execução penal é uma fase processual em que se executa o título judicial, com vistas a atingir os objetivos da pena. Apesar de ser o reflexo do poder punitivo do Estado, não se limita a cumprir as disposições da sentença condenatória, pois está ainda incumbida de, ao fazê-lo, aplicar os princípios e as garantias constitucionais inerentes ao cumprimento da sanção. 
Nesse sentido, necessário que todos os órgãos da execução estejam conscientes de que a sanção penal tem como finalidade reprimir a prática de condutas criminosas e prevenir seu cometimento. No panorama contemporâneo do direito penal, em específico o caráter preventivo da pena transcende o simples medo da punição, mas também se refere ao dever estatal de ofertar condições para reinserir o indivíduo transgressor na vida em sociedade. De outro modo, trata-se da busca por uma harmônica integração social do condenado, diretriz constante do art. $1^{\mathrm{o}}$ da Lei de Execução Penal.

Assim, a remição da pena surge como importante ferramenta de reinserção do preso na vida em sociedade, notadamente porque beneficia os indivíduos que se dedicam rotineiramente ao trabalho e ao estudo durante o período em que estão privados de liberdade. Mais que uma obrigação imposta aos apenados (arts. 18 e 31, LEP), o desempenho de atividades laborativas e a frequência ao ensino básico são direitos sociais protegidos constitucionalmente e, como tal, compõem seu mínimo existencial na dimensão sociocultural.

Como decorrência do próprio direito fundamental à educação, mais recentemente a remição pela leitura foi admitida pela prática forense como uma forma de desconto de pena. Apesar dos avanços, somente houve uma disciplina nacional unificada sobre o assunto com a edição da Resolução no 391, de 10 de maio de 2021, pelo Conselho Nacional de Justiça. A partir dessa normativa, é perceptível o incentivo à formação intelectual e profissional do apenado, notadamente porque o acesso à literatura e à informação complementa os esforços pedagógicos empenhados com a oferta dos demais níveis de ensino às pessoas presas.

Mais que fornecer subsídio para o desenvolvimento pessoal e formativo do preso, nota-se que o incentivo à leitura contribui para o enfrentamento das mazelas do Estado de Coisas Inconstitucional que atinge o sistema prisional brasileiro. Em um ambiente marcado por violações reiteradas aos direitos fundamentais e pela falta de estrutura para a manutenção dos estabelecimentos, o fortalecimento de programas de formação cultural pelo acesso aos livros pode ser um meio de amenizar o impacto do cárcere sobre os apenados. 
Assim, a remição da pena e, em especial, a remição pela leitura, podem ser vistas como notáveis conquistas do direito penal contemporâneo. A partir delas, é possível promover a reinserção do transgressor na vida em sociedade, ao mesmo tempo em que se concretiza a garantia fundamental de individualização da pena. $\mathrm{O}$ acesso às obras literárias, ao mesmo tempo, permite a oferta ao preso de uma formação cultural completa, que lhe fornece bases para evitar novas condutas delitivas. Desse modo, contribui-se para o alcance das efetivas finalidades da sanção criminal, ao passo em que se fornece uma alternativa idônea para resguardar direitos no cenário de crise estrutural do sistema penitenciário brasileiro.

\section{REFERÊNCIAS}

AVENA, Norberto Cláudio Pâncaro. Execução penal: esquematizado. 2. ed. São Paulo: Método, 2015.

BECCARIA, Cesare. Dos delitos e das penas. Lisboa: Fundação Calouste, 1988.

BITENCOURT, Cezar Roberto. Tratado de direito penal: parte geral. 17. ed. rev. ampl. e atual. São Paulo: Saraiva, 2012. v. 1.

BRASIL. Lei $\mathbf{n}^{\mathbf{0}}$ 7.210, de 11 de julho de 1984. Institui a Lei de Execução Penal. Brasília, DF: Congresso Nacional, 11 jul. 1984. Disponível em: http://www.planalto.gov.br/ccivil_03/leis/17210.htm. Acesso em: 05 jun. 2021.

BRASIL. Conselho Nacional de Justiça. Recomendação no 44, de 26 de novembro de 2013. Dispõe sobre atividades educacionais complementares para fins de remição da pena pelo estudo e estabelece critérios para admissão pela leitura. Brasília, DF: Conselho Nacional de Justiça, 26 nov. 2013. Disponível em: https://atos.cnj.jus.br/files//recomendacao/recomendacao_44_26112013_27112013160533.pdf. Acesso em: 13 jun. 2021.

BRASIL. Conselho Nacional de Justiça. Resolução no 391, de 10 de maio de 2021. Estabelece procedimentos e diretrizes a serem obser- 
vados pelo Poder Judiciário para o reconhecimento do direito à remição de pena por meio de práticas sociais educativas em unidades de privação de liberdade. Brasília, DF: Conselho Nacional de Justiça, 10 maio 2021. Disponível em: https://atos.cnj.jus.br/files/origina$112500220210511609 a 7 d 7 a 4 f 8 d c . p d f$. Acesso em: 13 jun. 2021.

BRASIL. Superior Tribunal de Justiça (Quinta Turma). Habeas corpus 181.099/SP.Paciente condenado definitivamente pelo crime de extorsão mediante sequestro, que, ao resgatar a pena de 15 anos de reclusão, praticou falta grave (posse de celular), motivo pelo qual o MM. Juízo das Execuções, nos autos de execução n. ${ }^{\circ}$ 788.634, declarou a perda do direito ao tempo remido e o reinício da contagem do prazo de cumprimento de pena para fins de benefícios. [...]. Impetrante: Francisco Juciangelo da Silva Araújo. Impetrado: Tribunal de Justiça do Estado de São Paulo. Paciente: Fábio Oliveira Silva. Relatora: Ministra Laurita Vaz, 02 de agosto de 2012 e publicado em 13 de agosto 2012. Disponível em: https://scon.stj.jus.br/SCON/GetInteiroTeorDoAcordao?num registro $=201001423814 \& d t \_$publicacao $=13 / 08 / 2012$. Acesso em: 23 jun. 2021.

BRASIL. Superior Tribunal de Justiça. Súmula 341. A frequência a curso de ensino formal é causa de remição de parte do tempo de execução de pena sob regime fechado ou semiaberto. Brasília, DF: Superior Tribunal de Justiça, 27 jun. 2007. Disponível em: https://www.stj.jus. br/docs_internet/revista/eletronica/stj-revista-sumulas-2012_29_capSumula341.pdf. Acesso em: 20 jun. 2021.

BRASIL. Supremo Tribunal Federal (Segunda Turma). Agravo regimental no habeas corpus $190.806 / S C$. A tese defensiva encontra respaldo na legislação de regência, pois, para o cálculo de dias remidos pelo estudo, a Recomendação 44, do Conselho Nacional de Justiça (CNJ), orienta-se pelos parâmetros previstos na Resolução 3/2010, do Conselho Nacional de Educação (CNE) [...]. Agravante: Juliana da Silva Ferreira. Relator: Ministro Ricardo Lewandowski, julgado em 30 de março 2021 e publicado em 02 de junho de 2021. Disponível em: https://redir. stf.jus.br/paginadorpub/paginador.jsp?docTP $=\mathrm{TP} \& \operatorname{doc} \mathrm{ID}=756029713$. Acesso em: 20 jun. 2021. 
BRITO, Alexis Couto de. Execução penal. 6. ed. São Paulo: Saraiva Educação, 2020.

DOTTI, René Ariel. Bases alternativas do sistema de penas. São Paulo: Revista dos Tribunais, 1998.

LEAL, João José. Algumas questões polêmicas acerca da remição penal. In: NUCCI, Guilherme de Souza; MOURA, Maria Thereza Rocha de Assis. Doutrinas essenciais: processo penal. São Paulo: Revista dos Tribunais, 2012. v. 6.

MARCÃO, Renato. Curso de execução penal. 18. ed. São Paulo: Saraiva Educação, 2021.

MIRABETE, Julio Fabbrini. Execução penal. 9. ed. São Paulo: Atlas, 2000 .

NUCCI, Guilherme de Souza. Código penal comentado. 20. ed. Rio de Janeiro: Forense, 2020.

NUCCI, Guilherme de Souza. Curso de execução penal. 4. ed. Rio de Janeiro: Forense, 2021.

OÑORO, Carmen dos Santos; SPEXOTO, Mário Eduardo Bernardes. Educar para libertar: a educação por meio da leitura e a incessante busca pela ressocialização dos presos. Revista de direito constitucional e internacional, v. 28, n. 121, p. 13-30, set./out. 2020. Disponível em: http://dspace.mj.gov.br/handle/1/4209. Acesso em: 20 jun. 2021.

ROIG, Rodrigo Duque Estrada. Execução penal: teoria crítica. 2. ed. São Paulo: Saraiva, 2016.

SARLET, Ingo Wolfgang; MARINONI, Luiz Guilherme; MITIDIERO, Daniel. Curso de direito constitucional. 6. ed. São Paulo: Saraiva, 2017.

SOUZA, Miguel Teixeira. Estudos sobre o novo processo civil. 2. ed. Lisboa: Lex, 1997. 
REGRAMENTO nacional trará mais segurança jurídica e estímulo à leitura por presos em SC. Notícias do Poder Judiciário de Santa Catarina, Florianópolis, 12 maio 2021. Disponível em: https:/www.tjsc. jus.br/web/imprensa/-/regramento-nacional-trara-mais-seguranca-juridica-e-estimulo-a-leitura-por-presos-em-sc. Acesso em: 23 maio 2021.

Recebido em: 30/06/2021

Aprovado em:10/08/2021 